\title{
Endoscopic management of gastric perforation caused by a foreign body
}

\author{
Ioannis Kalantzis ${ }^{\text {, }}$ Eustathios Georgopoulos ${ }^{b}$, Eudokia Katsanou ${ }^{b}$, Konstantinos Goumas ${ }^{a}$ \\ Korgialeneio-Mpenakeio Hellenic Red Cross Hospital, Athens, Greece
}

A 56-year-old female presented to the emergency department complaining of a 2-day history of epigastric pain and fever up to $38^{\circ} \mathrm{C}$. Because of localized but not rebound tenderness in the epigastric region, as well as elevated C-reactive protein combined with leukocytosis, a computed tomography scan of the abdomen was performed and revealed the presence of a radiopaque foreign body in the gastric antrum, penetrating through the full thickness of the gastric wall with surrounding extra-luminal free air and liquid (Fig. 1 A,B).

During upper gastrointestinal endoscopy, a sharp elongated $4 \mathrm{~cm}$ long foreign body (chicken bone) was detected in the anterior wall of the prepyloric antrum, penetrating the gastric wall (Fig. 2A). The chicken bone was removed with a snare (Fig. 2C) and 3 metallic clips were placed at the point of perforation (Fig. 2B). The patient received wide-spectrum antibiotics and was discharged after 5 days of hospitalization.

The majority of ingested foreign bodies pass spontaneously through the gastrointestinal tract, with less than $1 \%$ of cases requiring surgical intervention [1]. The most common regions of perforation are the ileocecal area and the colon, while gastric or duodenal perforation is not encountered as a frequent complication [2]. Although immediate surgical treatment remains the traditional treatment of choice, isolated cases of successful endoscopic treatment of gastrointestinal perforation by a foreign body are reported in the literature [3]. The role of

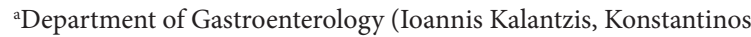
Goumas); $2^{\text {nd }}$ Department of Surgery (Eustathios Georgopoulos, Eudokia Katsanou), Korgialeneio-Mpenakeio Hellenic Red Cross Hospital, Athens, Greece

Conflict of Interest: None

Correspondence to: Ioannis Kalantzis MD M.Sc. Department of Gastroenterology, Korgialeneio-Mpenakeio Hellenic Red Cross Hospital, 2 Athanasaki Street, Athens, Greece,

e-mail: johnkalantzis@hotmail.com

Received 4 January 2019; accepted 22 January 2019;

published online 15 February 2019

DOI: https://doi.org/10.20524/aog.2019.0361

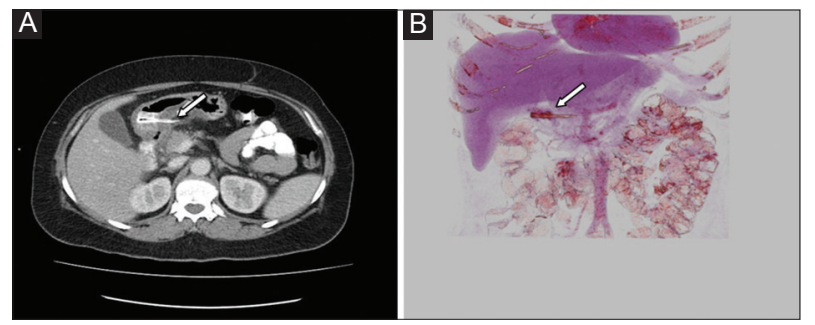

Figure $1(\mathrm{~A}, \mathrm{~B})$ Computed tomography scan of the abdomen, revealing the presence of a radiopaque foreign body in the gastric antrum, penetrating the gastric wall with surrounding extra-luminal free air and liquid
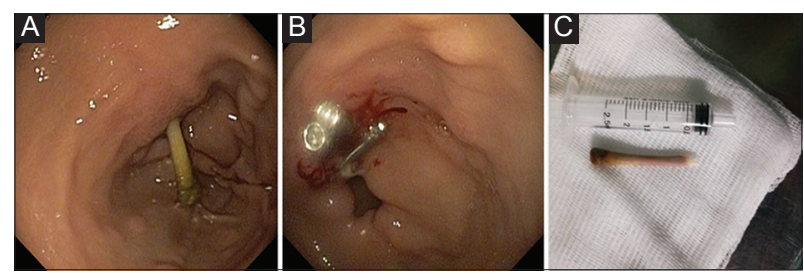

Figure 2 (A) Presence of a foreign body penetrating the gastric wall of the antrum in the prepyloric area. (B) Placement of 3 metallic clips at the point of gastric perforation. (C) Removed $4 \mathrm{~cm}$ long foreign body (chicken bone)

endoscopy in cases of perforation by a foreign body remains controversial but probably promising.

\section{References}

1. Ikenberry SO, Jue TL, Anderson MA, et al. ASGE Standards of Practice Committee. Management of ingested foreign bodies and food impactions. Gastrointest Endosc 2011;73:1085-1091.

2. Goh BK, Chow PK, Quah HM, et al. Perforation of the gastrointestinal tract secondary to ingestion of foreign bodies. World J Surg 2006;30:372-377.

3. Kim JS, Kim HK, Cho YS, et al. Extraction and clipping repair of a chicken bone penetrating the gastric wall. World J Gastroenterol 2008;14:1955-1957. 